
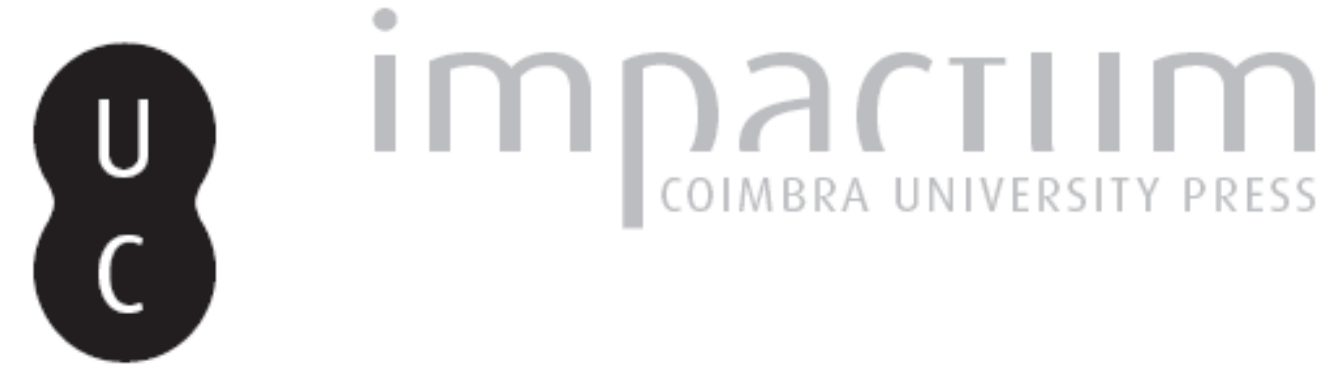

\title{
Prosopografía de Lusitania Romana: Flaminicae et Feminae Notabiles Lusitaniae
}

Autor(es): $\quad$ de Frías, Manuel Salinas; Rodríguez Cortés, Juana

Publicado por: Faculdade de Letras da Universidade de Coimbra/Imprensa da Universidade de Coimbra

persistente: URI:http://hdl.handle.net/10316.2/41875

DOI: DOI:https://doi.org/10.14195/1647-8657_55_12

Accessed : $\quad$ 26-Apr-2023 15:08:49

A navegação consulta e descarregamento dos títulos inseridos nas Bibliotecas Digitais UC Digitalis, UC Pombalina e UC Impactum, pressupõem a aceitação plena e sem reservas dos Termos e Condições de Uso destas Bibliotecas Digitais, disponíveis em https://digitalis.uc.pt/pt-pt/termos.

Conforme exposto nos referidos Termos e Condições de Uso, o descarregamento de títulos de acesso restrito requer uma licença válida de autorização devendo o utilizador aceder ao(s) documento(s) a partir de um endereço de IP da instituição detentora da supramencionada licença.

Ao utilizador é apenas permitido o descarregamento para uso pessoal, pelo que o emprego do(s) título(s) descarregado(s) para outro fim, designadamente comercial, carece de autorização do respetivo autor ou editor da obra.

Na medida em que todas as obras da UC Digitalis se encontram protegidas pelo Código do Direito de Autor e Direitos Conexos e demais legislação aplicável, toda a cópia, parcial ou total, deste documento, nos casos em que é legalmente admitida, deverá conter ou fazer-se acompanhar por este aviso.

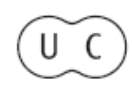


CONIMBRIGA

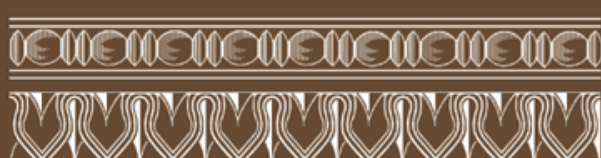

INSTITUTO DE ARQUEOLOGIA

VOLUME LV • 2016

FACULDADE DE LETRAS
UNIVERSIDADE DE COIMBRA 


\author{
Manuel SAlinas de Frías \\ Universidad de Salamanca (Proyecto HAR2014-55631P) \\ vafio@usal.es \\ JUANA RODRÍGUEZ CORTÉS \\ Universidad de Salamanca (Proyecto HAR2014-55631P) \\ juanar@usal.es
}

PROSOPOGRAFÍA DE LUSITANIA ROMANA.

FLAMINICAE ET FEMINAE NOTABILES LUSITANIAE

"Conimbriga" LV (2016) p. 221-250

https://doi.org/10.14195/1647-8657_55_12

RESUMEN: Prosopografía de las flaminicae locales y provinciales de Lusitania romana, a las que se añaden las mujeres notables de la provincia, bien por ser familiares de magistrados o por realizar actos importantes de evergetismo.

Palabras Clave: Prosopografía, epigrafía, Lusitania romana, culto imperial, evergetismo.

ABSTRACT: Prosopography of local and provincial flaminicae of Roman Lusitania, which the remarkable women of the province are added, either because they are relatives of magistrates or making important acts of evergetism.

KeYwords: Prosopography, Epigraphy, Roman Lusitania, Imperial Cult, Evergetism.

RESUmo: Prosopografia das flaminicae locais e provinciais de Lusitânia romana, a que se juntam as mulheres notáveis da província, ou 
porque são parentes de magistrados ou por realizarem importantes actos de evergetismo.

PALAVRAS-CHAVE: prosopografia, epigrafia, Lusitânia romana, culto imperial, evergetismo. 


\section{PROSOPOGRAFÍA DE LUSITANIA ROMANA. FLAMINICAE ET FEMINAE NOTABILES LUSITANIAE.}

La Prosopografía de Lusitania romana (PROLUR) es un proyecto de investigación emprendido por el Grupo de Investigación Reconocido (GIR) Hesperia de la Universidad de Salamanca. El proyecto pretende, como su nombre indica, elaborar una prosopografía de los personajes notables de la provincia romana de Lusitania que sirva de material de consulta a todos aquellos estudiosos interesados en obtener una información rápida y precisa sobre un determinado sujeto de la élite hispanorromana de la provincia. Dicho de una manera coloquial, se trata de realizar el who is who? de Lusitania romana.

Para el caso de los individuos varones la prosopografía, una disciplina con larga tradición académica, no ofrece problemas. Quedan incluidos en ella, ipso facto, todos aquellos sujetos que han desempeñado magistraturas locales o provinciales. Estudios como los de J. A. Delgado Delgado (Delgado 1999 y 2000) sobre los flamines del culto imperial, Marta González Herrero sobre los equites provinciales (GoNzÁlez Herrero 2006) o Leonard Curchin (CURCHIN 1990 y 2015) sobre los magistrados locales proporcionan respectivamente un estado de la cuestión sobre sus objetivos.

Pero para lo que respecta a las personas de sexo femenino la situación es más complicada. No existen dudas en la actualidad sobre la importancia de los estudios de género y de la historia de la mujer para la comprensión de la Historia en general. En el caso del mundo romano, sin embargo, la elaboración de una prosopografía tropieza con el obstáculo de que la mujer fue siempre un ciudadano de segunda categoría que no tuvo nunca plenitud de derechos civiles. Como tal, la mujer estaba excluida del ejercicio de las magistraturas y, en general, del espacio público social. Para hacerse visible en este ámbito la mujer sólo disponía de dos medios: por una parte el desempeño de determinados sacerdocios vinculados a algunos cultos tradicionales (Mater Matuta por 
ejemplo) o al culto imperial (flaminicae municipales o provinciales); por otra parte, su asociación con un varón, normalmente de su propia familia (padre, esposo o hijo), en epígrafes conmemorativos o funerarios que eran objeto de exposición pública en el foro, vias públicas o cementerios. Este último procedimiento, generado en Roma e Italia, rápidamente fue imitado en las provincias (MIRÓN 1996; NAVARRo CABALLERO 2001 y 2003; ImMONGAUlt 2006).

En la confección de esta Prosopografía femenina hemos tenido en cuenta, en primer lugar, obviamente, a las mujeres que han desempeñado el sacerdocio del culto imperial (flaminicae), local o provincial, por su condición de cuasi magistratura. En segundo lugar a aquellas mujeres que expresan un vínculo familiar con un varón que ha desempeñado alguna magistratura correspondiente a alguno de los ordines de la sociedad romana, en el entendido de que el estatuto jurídico político de un varón se transmitía a sus familiares directos, incluyendo los femeninos, como indican las leyes municipales que regulan el otorgamiento de la ciudadanía (lex mun. Salpensani rub. 20 y 21, CIL II 1963 = ILS 6088). En tercer y último lugar hemos incluido también a aquellas mujeres que realizan determinadas liberalidades como la donación de estatuas, la redención de impuestos, la financiación de banquetes públicos, etc., que por su cuantía evidencian la situación socialmente preeminente de estas personas (Melchor Gil 2009) que, de haber sido varones, hubieran podido jugar un papel político más destacado que las leyes romanas le han negado. Conmemorando a sus hijos o maridos, apoyándolos, contribuyendo a sus gastos, estas mujeres han jugado también un papel político, no sólo social, en su momento.

Por el contrario, no hemos incluido a aquellas mujeres que sufragan gastos, normalmente de índole funeraria, con la expresión de suo, o haciendo constar su condición de heres, ya que estas expresiones no quieren decir necesariamente que sean mujeres influyentes desde el punto de vista social. El hecho de que a menudo aparezcan asociadas a otras personas en estos gastos parece indicar una condición económicamente modesta, lo que las excluye de una prosopografía.

En la elaboración del elenco siguiente, por razones de brevedad y claridad expositiva, se citan solamente los principales repertorios epigráficos de acuerdo con sus abreviaturas habituales, que aparecen recogidas al final del artículo. La bibliografía menor (artículos de revista, capítulos de libro, etc.) solamente se cita cuando aporta alguna modificación importante a la lectura de las inscripciones desde el punto 
de vista prosopográfico. En todo caso, toda esta bibliografía menor se cita en la Bibliografía final, lo mismo que las citas puntuales que se realizan en el estudio de cada personaje particular. De la misma manera, no se dan todas las referencias a la edición on line de la base de datos de Hispania Epigraphica (HEpOl), salvo cuando proporciona alguna corrección o precisión importante para la prosopografía.

\section{Flaminicae Lusitaniae}

\section{CAELIA VEGETA}

Lisboa, Olisipo: CIL II 197 = 5218; AE 1953, 255; ILER 4453; DE Francisco 1989, 129; Curchin 1990, 369; Gallego Franco 1991, 225; Delgado 2000, 138, no 16; Rodríguez y Salinas 2000, 252 $\mathrm{n}^{\circ}$ 9; HEpOl 20924 con foto, propone leer C(aiae) Aeliae Vegetae con tria nomina.

[Cae]liae [...f(iliae?)]/Vegeta[e]/ flaminic[ae]/ M(arcus) Gellius/Rutilianu[s]/ maritus.

Basa de estatua en piedra calcárea. Lisboa, Museo Nacional de Arqueología. La inscripción debe datarse, por criterios prosopográficos, en época de Adriano, ya que M. Gellius Rutilianus fue IIvir de Olisipo en los años 121-122 (CIL II 186, 4992). El nomen de la flaminica presenta problemas: HüBNER restituía Caeliae, que es lo que seguimos nosotros, y VASCONCELOS 1927-29 nº 26, Caeliae o Aeliae. E1 antropónimo Caelius/a está abundantemente atestiguado en Hispania y en Lusitania en particular (ABASCAL 1994a, p. 102; AALR p. 124-125, s.v.). Lambrino 1951, restituye [Gel]liae, que aceptan De Francisco 1996 y Delgado 2000; sin embargo, nos parece poco probable que su nomen sea el mismo que el de su marido, ya que las gentes romanas son exógamas.

\section{DOMITIA PROCULINA}

Talavera de la Reina, Caesarobriga:. CIL II 895; BRAH 2, 1882, p. 258; ILS 6895; ILER 1661; Del Hoyo 1987 115-116; De Francisco 1989, 136; Gallego Franco 1991, p. 226; Abascal 1994b, 385; DelGado 1999, 453, no 13; Delgado 2000, 136-137, n 13; RodríGuez y Salinas 2000, 252, no 3; HEpOl 282; AbasCAL y AlFöldy 2015, no 124.

Domitia L(uci) f(ilia)/ Proculina/ [f]laminica Provin[c(iae)]/ Lusitan(iae) et flamini(ca)/[m]unicipi sui prim[a]/ et perpetua.../[...]. 
Pedestal que conserva huellas de los anclajes de las imágenes. Madrid, Museo Arqueológico Nacional. FITA, en $B R A H 2$, 1882, añade un renglón: [COL(onia)/ EMERITENSIS D.D.] que no se conserva. ETIENNE 1958, 239, la data en época de Vespasiano: 70-79. Si como creen HÜBNER (CIL II, p. 112) y WIEGELS, p. 74, esta flaminica estaba emparentada con Domitia Attia, esposa de L. Annius Placidus, duovir ter también en Caesarobriga, perteneciente a la tribu Quirina (CIL II 896), no puede ser anterior, efectivamente, a la época Flavia. La posición relevante de Proculina se observa en su condición de flaminica prima et perpetua, pudiendo ser el primero de los atributos un indicio de fecha relativamente temprana tras la conversión municipal de Caesarobriga. Del Hoyo opina que el adjetivo perpetua parece honorario, sin dar razones de ello. Creemos más probable que refleje una situación real.

\section{FLAVIA RUFINA}

Alcácer do Sal, Salacia: CIL II 32; ILS 6893; ILER 49; IRCP 183; Del Hoyo 1987 116-118; RAP 267; De Francisco 1989, 125; Gallego Franco 1991, 226; Saquete 1997, 173 no 18; Delgado 1999, 454, ${ }^{\circ}$ 14; Delgado 2000, 137, $\mathrm{n}^{\circ}$ 14; RodríGuez y Salinas 2000, 252, $\mathrm{n}^{\circ} 4$.

Iovi O(ptimo) M(aximo)/ Flavia L(uci) f(ilia) Rufina/ Emeritensis fla/minica Provinc(iae)/Lusitaniae item Col(oniae)/Emeritensis/ perpet(ua)/ et municipi Salacien(sis)/d(ecreto) d(ecurionum).

Ara de mármol. Évora, Museo Regional. En una cara hay un águila en relieve y en la otra un árbol (¿un roble, en relación con Júpiter?). Basándose en el nomen, ETIENNE 1958, pp. 167, 238, la data en época Flavia, suponiendo que la familia habría recibido la ciudadanía de Vespasiano. Del Hoyo supone que pudo llegar a Salacia por matrimonio. Había estrechas relaciones entre Salacia y Mérida, donde se registra la presencia de salacienses (CIL II 518). Delgado 1999, 455, estima poco conclusivas las razones de ETIENNE y cree que, en todo caso, no es anterior a Vespasiano.

\section{HELVIA}

Mérida, Emerita: VelázQuEz en Anas 1, 1988, 125-130; AE 1989, 396; HEp 2, 1990, n. 40; Saquete 1997, 173 n 21; Delgado 1999, 455, n 15; RodríGuez y SaLinas 2000, 252, nº 6; HEpOl 18930.

Helvia M[...f(iliae?)]/ flamin(ica)/ Provinc(iae)/ [Lusitaniae]/ $h$ (ic) [s(ita) e(st) s(it) t(ibi) t(erra) l(evis)].

Conimbriga, 55 (2016) 221-250 
Placa de mármol blanco. Mérida, MNAR. Época flavia o antonina según A. Velázquez, Anas 1, 1988, quien fue su descubridor. DelGADO 1999 cree que no hay criterios para una datación mínimamente precisa. Los Helvii están muy bien atestiguados en Lusitania, donde debieron ser una familia de implantación antigua, particularmente en Mérida (ABASCAL 1994, 148-149; AALR p. 190-191, s.v.).

\section{IULIA MODESTA}

a) Bobadela (Oliveira do Hospital, Coimbra): CIL II 396; ILER 463; Del Hoyo 1987, 191-193; De Francisco 1989, 132; RAP 421; Gallego Franco 1991, 199, 214, 226; Delgado 1999, 447, nº 3; HEpOL 18955.

Pietati sacrum/Iulia Modesta ex patrimonio suo in honorem gentis/Sex(ti) Aponi Scaevi Flacci mariti sui flaminis Provinc(iae)/ Lusit(aniae) et in honorem gentis Iuliorum parentum suorum.

Coimbra, Museu Machado de Castro. Pedestal de estatua, dedicada a Pietas. La estatua debía ser un monumento lo suficientemente importante como para constituir un objeto de emulación con el sacerdocio provincial desempeñado por el cónyuge y de exaltación, a la vez, de la propia gens de la dedicante. La elección de Pietas en relación con la conmemoración de los padres era algo especialmente acertado y significativo (RoDRíGUEZ CORTÉs 2003).

b) Bobadela (Oliveira do Hospital, Coimbra): CIL II 397, p 817; ILER 6080; Del Hoyo 1987, 189-193; De Francisco 1989, 132; RAP 548; Rodríguez y Salinas 2000, 252, n 10; HEp 13, 2003/2004, 976; HEpOl 18956.

[...] has portas et porticus refecit et donavit / splendidissimae civitati Iulia Modesta / flaminica Provinc(iae) Lusit(aniae) ex patrimonio suo.

El epígrafe ha desaparecido, por lo que la reconstrucción del texto es hipotética. ANDREU 2004 pp. 87, 88, $244 \mathrm{n}^{\circ} 75$ supone que se trataría de una restauración de las puertas del foro. Es posible que esta inscripción sea posterior en el tiempo a la primera, ya que en aquella no se menciona el flaminado provincial.

6. LABERIA GALLA

Leiria, Collippo: CIL II 339; ILER 1774; BRANDÃo 1972, 61-66 no 4; IRCP 443; Del Hoyo 1987, 118-120; De Francisco 1989, 131; RaP 547; Delgado 1999, 455, $\mathrm{n}^{\circ} 16$; Delgado 2000, 140, $\mathrm{n}^{\circ} 22$; Ro- 
DRÍGUez y Salinas 2000, $252 \mathrm{n}^{\circ}$ 5; Canto 2004, $281 \mathrm{n}^{\circ}$ 7; ANDreu 2004, 245 n 76; HepOl 21392; D'ENCARNAÇÃo 2014.

Laberiae L(uci) f(iliae) Gallae/ flaminicae Ebore(n)si/ flaminicae Prov(inciae) Lusi/ taniae impensam fune/ris locum sepulturae/ et statuam d(ecreto) d(ecurionum) Colli/ ponensium datam L(ucius)/ Sulpicius Claudianus/ [...].

Perdida. Es posible que L. Sulpicius Claudianus fuera su marido y natural de Collippo, donde se conoce un IIvir con el mismo nomen, C. Sulpicius Silonianus (CIL II 5232), estando ambos posiblemente relacionados con dos Sulpicii militares de esta área (CIL II 403, 5238). Teniendo en cuenta estos hechos, es probable que Laberia Galla fuese natural, no de Collippo, como se ha supuesto, sino de Ebora, donde alcanzó el flaminado local, recibiendo honores fúnebres en la civitas de su esposo probablemente como consecuencia de la influencia social del mismo (vide infra III E). Recientemente, J. D'ENCARNAÇ̃̃o 2014 ha argumentado vigorosamente contra la autenticidad del epígrafe, que sería una falsificación de Resende, por lo que habría que excluir a Laberia Galla de la lista de flaminicae lusitanas.

\section{SERVILIA L. f. ALBINI}

Lisboa, Olisipo: CIL II 195; ILER 1660; Del Hoyo 1987, 120123; De Francisco 1989, 130; Gallego Franco 1991, 229; RAP 538; Lefebvre 2001; Delgado 1999, 456, $\mathrm{n}^{\circ} 17$; Rodríguez y Salinas 2000, 252 n $^{\circ}$ 1; $A E$ 2001, 1132; AE 2005, 730; HEp 14, 2005, 445; Stylow y Ventura 2005, 36-46; GonzÁlez Herrero 2005; eadem 2006, 55-61, no 9; HEpOl 21284; Álvvarez Melero 2008, 85-89.

Flaminicae/ Provinciae/ Lusitaniae/ Serviliae L(uci) f(iliae)/Albini d(ecreto) d(ecurionum)// Lucceiae/ Q(uinti) f(iliae) Albinae/ Terentiani/d(ecreto) d(ecurionum).

Pedestal, perdido actualmente. ETIENNE 1958, 166, recogiendo una propuesta de Marchetti, propuso relacionarla con el flamen provincial Albinus Albui f. (CIL II 473; Álvarez en MMAP 4, 1943, 45), que el sabio francés databa bajo Claudio. En el caso de éste, la ausencia de praenomen probaría su condición de peregrino antes de desempeñar el sacerdocio, lo cual le habría otorgado la ciudadanía; ello explicaría que Servilia L. $f$. fuera hija de L. Albinus, ya con tria nomina, y la fecharía también en época de Claudio. Del Hoyo, 1987 p. 122, cree que el genitivo Albini debe entenderse como referido al marido de Servilia. LefÈvRe 2001, propuso reconocer en él a un hipotético Q. Lucceius 
Albinus, flamen provinciae Lusitaniae, que sería en realidad el esposo de Servilia, constituyendo ambos una pareja de magistrados religiosos provinciales y siendo Lucceia Albina hija de ambos. Contra esta propuesta obra el hecho, demostrado por DelGado 1999, de que no parecen existir flaminicae provinciae Lusitaniae antes de Vespasiano. GonZÁLEZ Herrero 2005, por su parte, identifica a Q. Lucceius Albinus con un abogado mencionado en cartas de Plinio el Joven, en época de Trajano, al que supone natural de Olisipo, aunque no existen pruebas de ello. Gallego Franco reconstruye el nombre como Servilia [Albina] (vide infra $\left.\mathrm{n}^{\circ} 24\right)$.

\section{VALERIA VINICIANA}

Mérida, Emerita: CIL II 494; ILER 5312; ERAE 113; Del Hoyo 1987, 195-197; De Francisco 1989, 135; Saquete 1996, 173 no 17; Delgado 2000, 142-143, no 30; RodríGuez y Salinas 2000, 252 nº 7 ; HEp 11, 2001, 64; EDMONDSON 2001, 170-172, no 24.

$H$ (ic) $s$ (itus) e(st). D(is) M(anibus) s(acrum). s(it) v(obis) t(erra) l(evis)/ G(aius) Valerius Hymineus emeritensis c(ivis) R(omanus)/ Val(eriae) Vini[c]ianae flam(inicae) perp(etuae) libertus/ sibi et uxori se vivo fecit et dedicavit/ Cam(ila?) Chrysampelis ann(orum) LV Vini[c]iana ann(orum) XXXV H(ymineus) a (nnorum) $L X$.

Monumento funerario en forma de aedicula con tres bustos de los difuntos. En la actualidad perdido. EDMONDSON corrige la lectura de Moreno de Vargas, que es quien da a conecer la inscripción en el s. XVII, de la siguiente manera: lin. 1: hic siti sunt; lin. 5: Cam(eria [sive Cam(ilia)].

No incluimos en nuestra relación a FL(AVIA) TYCHE: Lisboa, Olisipo: CIL II 179; ILS 4099; ILER 376; RAP 460; Delgado 2000, p. $137, \mathrm{n}^{\circ} 15$. Es cernophor (a) del culto a Cibeles. Puede tratarse de una liberta y de un culto privado que no implica, por sí mismo, una posición social alta.

\section{Feminae notabiles}

\section{ALLIA MAXUMA}

Alburquerque: CIL II 724; EE IX 119; IMBA 2; RoDRíGuEZ y SALINAS 2000, 254; ANDreu 2004, 199-200 n 1; CURCHIN Supplementum $53 n^{\circ} 393$ :

Conimbriga, 55 (2016) 221-250 
G(aio) Allio/ Quadrato / quaestori / VIIIvir(o) / G(aius) Allius Syria/cus pater et Al/lia Serani f(ilia) / Maxuma ma/ter f(aciendum) c(uraverunt).

Badajoz, Museo Provincial. Madre de G. Allius Quadratus, cuestor, octovir. STYLOw 1993, 43-44, plantea la posibilidad de que el octovirado fuera un colegio semejante al decemvirado, un modelo de magistratura traído por los inmigrantes itálicos, que se organizaron de esta forma en algunas comunidades peregrinas, tal vez una praefectura dependiente de Emerita o de Ammaia, distante sólo 40 kms al oeste. Hipotetiza además sobre la posibilidad de una lectura quaestor octovir(alis). El hecho de que este tipo de magistraturas tendieran a desaparecer con la regularización que supuso la municipalización Flavia, aboga por una fecha anterior al año 75 .

\section{ARTULLIA SEVERA}

S. Bartolomeu de Messines, Ossonoba: CIL II 8*, ILER 30; IRCP 60; Gallego Franco 197.

I(ovi) O(ptimo) M(aximo)/ in memoriam/L(uci) Atili Maximi/Severianifil(ii)/ pientissimi/L(ucius) Atil(ius) Atilianus/ et Artullia/G(aii) f(ilia) Severa ex/ [ar]genti lib(ris)/ [...] posuerunt.

Museu de Évora. Madre de M. Atilius Maximus Severianus y esposa de L. Atilius Atilianus, dedica junto con éste una estatua de plata a Júpiter en memoria de su hijo. Finales s. II- s.III. ILER lee en líneas 8-9: ex gentilib(us) posuerunt.

\section{ATTIA PATERNA}

Cáparra, Capera: CIL II 832; CMPC 280; ILER 4062; CPILC 2; Cerrillo 2006, 22-23; CRC 2; HEPoL 21771; CILC III 1008.

Attiae/ Paternae/M(arcus) Attius/Silvanus/pater/Caeria Se/vera mater/f(aciendum) c(uraverunt).

Pedestal que forma parte de la puerta del "olivar del Duque", en Abadía, aunque procedente de Cáparra. Hija de Caeria Severa, CILC III p. 96, la supone emparentada, dado que llevan el mismo cognomen, con Cocceia Severa (cf. $\left.n^{\circ} 12,16\right)$. Siglo II.

\section{AVITA MODERATI}

Cáparra, Capera: CIL II 813; EJER 152; ILER 6427; CPILC 186; RodríGuez 2005, 411 n 29; Cerrillo 2006, 19; HEpOL 19015; CRC 72; CILC III 1005. 
Avitae Modera/tif(iliae) aviae/ ob honorem quot/civis recepta est/ Caperae Cocceia/Celsi fil(ia) Severa/ Norbensis/cura et impensa/Avitae Modera/ti aviae suael posuit.

Madrid, Museo Arqueológico Nacional. Pedestal. Procede de las ruinas de Cáparra. Pertenece al conjunto de dedicatorias realizadas por Cocceia Severa a mujeres de su familia, que deben datarse a inicios del siglo II (CERRILlo 2006, cf. nº 16 a).

\section{CAERIA SEVERA}

Cáparra, Capera: CIL II 832; ILER 4062; CMPC 280; CPILC 2; HEPoL 21771; CRC 2; CILC III 1008.

Attiae/ Paternae/M Attius/Silvanus/ pater/Caeria Se/vera mater/ f(aciendum) c(uraverunt).

Vide $\mathrm{n}^{\circ} 11$. Caerius en masculino aparece también en Idanha-a-Nova (ILER 4433). La forma Caerus, que podría ser indígena y el origen del gentilicio, se documenta un poco más al norte, en Hinojosa de Duero y Yecla de Yeltes, en la provincia de Salamanca: AALR p. 126.

\section{CALPURNIA SABINA}

Évora, Ebora: CIL II 112; AE 1967, 130; ILER 6421; IRCP 382; DíAZ DE CERIO 2012, 334.

$D$ (is) M(anibus) s(acrum)/ Q(uinto) Iul(io) Maximo c(larísimo) v(iro)/quaestori prov(inciae) Sici/liae trib(uno) plebe(i) leg(ato)/ pro$v$ (inciae) Narbonens(is)/ Galliae praet(ori) des(ignato)/ ann(orum) XLVI/ Calpurnia Sabi/na marito optimo// Q(uinto) Iul(io) Claro c(larissimo) i(uveni) IIII viro/viarum curandarum/ann(orum) XXI/ Q(uinto) Iul(io) Nepotiano c(larissimo) i(uveni)/ IIII viro viarum curan/ darum ann(orum) XX/ Calpurnia Sabina filiis.

Calpurnia Sabina era esposa de Quinto Julio Máximo. EtIEnNe 1965, tuvo ocasión de examinar la carrera de este senador. El hecho de que a los 46 años, fecha de su muerte, sólo hubiera alcanzado la designación para la pretura muestra una carrera modesta dentro del clarisimado, tal vez por ser un novus senator, impresión que se refuerza por el hecho de que sus hijos habían comenzado por el escalón más bajo del vigintivirado. 


\section{CANIDIA ALBINA}

Évora, Ebora: CIL II 111, IRCP 381; GALlego Franco 213; DíAZ DE CERIO 2012, 325.

D(is) M(anibus)/ Canidiae Albinae/ c(larissimae) m(emoriae) f(eminae) matri Catin(ii)/Canidiani c(larissimae) m(emoriae) v(iro)/ consobrini sui/ Catinia M(arci) fil(ia)/ Aciliana c(larissima) f(emina)/ s(ua) p(ecunia) f(ecit).

Ara funeraria. Museo de Évora. IRCP 454-455 plantea la existencia en Évora de dos familias senatoriales de origen seguramente lusitano, las gentes Canidia y Catinia. De la gens Canidia se conoce otro testimonio en la misma Évora: ILER 5962. Con la gens Catinia se acostumbra a relacionar el consul suffectus del año 203, y ordinario del 204, L. Fabius Cilo Septiminus Catinius Acilianus Lepidus Fulcianus. Fecha: s. III (cf. no 16).

\section{CATINIA ACILIANA}

Évora, Ebora: CIL II 111, IRCP 381; Gallego Franco 213; DíAZ DE CERIO 2012, 335.

Vide $\mathrm{n}^{\mathrm{o}} 15$.

\section{COCCEIA SEVERA}

a) Cáparra, Capera: CIL II 813; EJER 152; ILER 6427; CPILC 186; RodríGuez 2005, 411, nº 29; CERrillo 2006, 19; HEpOL 19015; CRC 72; CILC III 1005.

Avitae Modera/ti filiae aviae/ ob honorem quot/ civis recepta est/ Caperae Cocceia/Celsi fil(ia) Severa/Norbensis/cura et impensa/Avitae Modera/ti aviae suae/ posuit.

Pedestal. Actualmente en el Museo Arqueológico Nacional, Madrid. Ver comentario al no 12: Avita Moderatif.

b) Cáparra, Capera: CIL II 814; ILER 1534; CPILC 371; RoDRíGUEZ 2005, 411, no 30; Cerrillo 2006, 20-21; HEpOl 19016; CRC 71; CILC III 1007.

Trebiae/ Proculae/ matri/ Cocceia Cel/si filia/ Severa/ Norbensis.

Pedestal. Actualmente desaparecido. Inscripción dedicada por Cocceia Severa en honor de su madre, Trebia Procula $\left(\mathrm{n}^{\mathrm{o}} 30\right)$. Nada autoriza a pensar, como hace CILC III, p. 95, que ésta hubiera fallecido en el momento de hacerse la inscripción.

c) Cáparra, Capera: CIL II 852; CMPC 279; ILER 4781; CPILC 
1; HEpOL 5306; Haba 1986, 24-27 nº 2; Cerrillo 2006, 21-22; CRC 1; CILC III 1006.

Trebiae/ Vegetae/ materterae/ Cocceia/ Severa/ Norbensis.

Pedestal de mármol blanco. Forma parte del arco de entrada del "olivar del Duque", en Abadía. Primera mitad o mediados del siglo II. Cf.: GonZÁlez Conde 2000.

Como hemos dicho antes, Cocceia Severa fue una mujer que desarrolló una gran actividad epigráfica conmemorando a otras mujeres de su familia: a su abuela materna Avita, a su madre Trebia Procula y a su tía Trebia Vegeta. Llama la atención la ausencia de varones. El hecho de que su abuela Avita carezca de nomen podría hacer suponer que era peregrina y que adquirió la ciudadanía de manera retroactiva al alcanzar alguno de los varones (tal vez su yerno, el marido de Trebia Procula) la civitas per honorem de acuerdo con lo dispuesto en el edicto de Vespasiano (lex mun. Salpensani rub. 20 y 21, CIL II $1963=$ ILS 6088). Cocceia se estableció en Capera (menciona su origo norbense) y atrajo a su abuela y, probablemente, a su tía. Se conoce un Victorinus, servus de C(occeia?) Severa, que dedica un exvoto a Ataecina en Malpartida de Cáceres (CIL II 5298), y un liberto, Cocceius Modestianus, documentado también en el mismo lugar, que tal vez lo sea de nuestra Cocceia (CIL II 5299). Este conjunto de epígrafes, realizados en mármol y no sobre granito como los ejecutados inmediatamente a la promoción municipal de la ciudad, marcan una segunda etapa en el embellecimiento y monumentalización de la misma, debiendo fecharse en la primera mitad del siglo II (CERRILLO 2006).

d) Los Santos de Maimona: Gómez-Pantoja y Madruga 2014, 247-265.

[.../...]/ Severa Norb(ensis)/ ann(orum) LXXX/ flaminica pro/ vinc(iae) Baeticae et/ Norbensium/ h(ic) s(ita) e(st) s(it) t(ibi) t(erra) l(evis).

Los editores del epígrafe proponen identificar a la difunta, que desempeñó un inusual flaminado provincial de la Bética además del flaminado en la colonia de Norba, con la dedicante de las inscripciones de Cáparra. La mayor dificultad para esta identificación está en la diferencia cronológica, ya que las otras dedicatorias, con buenas letras, parecen encajar en la primera mitad del siglo II, mientras que la factura mucho más irregular de este epígrafe les lleva a proponer una datación a comienzos del siglo III. La elevada edad de la difunta sin embargo permitiría quizás tender un puente entre las cronologías 
tan separadas. El flaminado probablemente lo alcanzaría a edad muy avanzada. De ser cierta la identificación, habría que colocar a Cocceia Severa entre las flaminicae lusitanas registradas en la primera parte de este artículo.

\section{DOMITIA ATTIA}

a) Talavera de la Reina, Caesarobriga: CIL II 896; FITA en BRAH 2, 1882, 259-260, no 6; FUIDIO 1934 127, 145, no 4 y 88; ILER 5271; Wiegels 74; AlFöldy 1987 59; CURChIN 1990 322; RodRÍGUEZ y SALINAS 2000 254; ABASCAL y ALFÖldy 2015122.

D(iis) M(anibus) s(acrum)/L(ucio) Annio Placi/do Quir(ina) Caesa/robrig(ensi) an(norum) XL/ aedil(i) quaesto/ri IIviro ter/ Domitia Attia/ marito optimo /fecit.

Talavera, en la fuente del jardín de las reales fábricas.

b) CIL II 897; FITA en BRAH 2, 1882, 260-263 nº 7; FuIDIO 1934 127, 145, nos. 5, 6 y 9; ILER 5272; Gamer 1989, 283; AbasCAL 1994b 385; ABASCAL y AlFöldy 2015, 129.

D(is) M(anibus) s(acrum) / Domitia Attia/ Caesarobrig(ensis)/ annor(um) XXVII / h(ic) s(ita) e(st) s(it) t(ibi) t(erra) l(evis)/ Annii Tagana / et Paulinus fili(i) f(aciendum) c(uraverunt).

Valencia, colección particular. Esposa de L. Annius Placidus, IIvir. Finales del siglo II o comienzos del III. Sobre la existencia de una importante gens Domitia en Caesarobriga, cf. comentario al $\mathrm{n}^{\mathrm{o}} 2$.

19. HEIA $[\ldots]$

Lisboa, Olisipo: CIL II 183; ILER 2062.

Neroni Claudio divi Claudi filio Ger[manici Caes(aris) nep(oti) Ti(berio) C]aesaris [pron(epoti) divi] Aug[usti abnepoti C]aesar[i] Aug(usto) Germanico pont(ifici) max(imo) trib(unicia) pot(estate) III imp(eratori) III co(n)s(uli) II designato III proscenium et orchestram cum ornamentis augustalis perpetuus C(aius) Heius Primus Cato/Heia $[\ldots]$.

Inscripción de finales del año 57, en que coinciden los títulos imperiales con la designación del tercer consulado de Nerón. La mujer es de condición liberta y comparte nomen con su esposo, lo que indica que pertenecieron al mismo propietario. La cuantiosa donación que efectúan muestra su elevado nivel económico (Melchor Gil 2009, 143). Los Heii se atestiguan en otra inscripción de Lisboa (CIL II 196) y en Archena, Murcia (CIL II 3541). 


\section{IULIA IUSTA}

Bucelas, Loures, Lisboa, Olisipo: CIL II 313; Fernandes 2003 pp. 28-33, no 1, fotos 1-2; HEp 13, 2003/2004, 998. CuRCHIN, Supplementum 1099.

D(iis) M(anibus) / L(ucii) Iuli(i) L(ucii) f(ilii) Galer(ia tribu) / Iusti aedilis / an(norum) XXVIII / L(ucius) Iulius Reburrus pate[r] / et Iulia Iusta mater / filio piissimo.

Madre de L. Iulius Iustus, edil. Finales del siglo I o siglo II d.C. El cognomen del marido, Reburrus, es de tradición indígena (AALR, $\mathrm{p}$. 279-289 s.v.)

\section{IULIA LUPERCA}

Cáparra, Capera: CIL II 834, 835; ILER 3717, 6136; AE 1967, 117; CPILC 377; S. HABA 1986, 128-129 nº 65; CuRCHIN 1990 323; RodríGUEZ y SALINAS 2000, 254; GonZÁlez Herrero 2002; ANDREU 2004, $201 \mathrm{n}^{\circ}$ 4; RodríGuez 2005, 412, no 33; Cerrillo 2006, 25 (foto); $H E$ pOl 21774; CRC 63; CILC III, 1004, Álvarez Melero 2008, 75-79 no 2.

Iuliae Luperci f(iliae)/ Lupercae M(arcus) Fidius/ Macer uxori p(onendum) i(ussit).

El epígrafe, dado por desaparecido durante mucho tiempo, ha sido vuelto a hallar por J. Esteban y A. Pajuelo, según noticia dada por el diario Hoy de Extremadura el 22 de mayo de 2016, adjuntando foto del epígrafe y los descubridores. Posiblemente formó parte del arco de Cáparra, haciendo pareja con la inscripción del lado derecho, dedicada también por M. Fidius Macer a Bolosea Pelli f(ilius) (CIL II 834). La fecha debe ser posterior al 74-75 d.C. si tenemos en cuenta que su marido fue mag(istratus) III y IIvir bis en Capera (BLÁzQuEz 1965, p. 59; GonzÁlez Herrero 2002); es decir, que vivió a caballo del momento de la transformación de la ciudad en municipium, desempeñando magistraturas antes y después de la promoción municipal.

\section{IULIA MARCELA}

Lisboa, Olisipo: CIL II 261; ILER 5550; Gallego Franco 214; Curchin 1990 376; Mantas 2005, 35; Curchin Supplementum 52 $\mathrm{n}^{\circ} 376$.

Dis Manibus/ Q(uinti) Caecili Q(uinti) f(ilii) Gal(eria) Caecili/ ani aedilis an(norum) $X X X X / M$ (arci) Caecili Q(uinti) f(ilii) Gal(eria) Aviti an(norum) XVIII/ Iulia M(arci) f(ilia) Marcella marito/ optumo filio piissimo de suo fecit.

Conimbriga, 55 (2016) 221-250 
Inscripción funeraria a su marido Q. Caecilius Caecilianus, edil, y a su hijo M. Caecilius Avitus, de suo.

\section{IULIA PERSICA}

Mérida, Emerita: AE 1952, 117; ERAE 145; MMAP 7, 1946, p. 39; Curchin 1990 350; TriLlmich et al. 1993, 298; Nogales 1997, 88-90; Rodríguez y Salinas 2000, 254; Delgado 2000, $\mathrm{n}^{\circ} 4$; Edmondson 2001, 120-123, nº 2; CURCHIN Supplementum 50 n $^{\circ} 350$.

D(is) M(anibus) s(acrum)/L(ucio) Antestio Persico Papirie Emeriten(si)/ ann(orum) XXXVII IIvirali pont(ifici) perpetuo/Iulia Persica et Antestius Avitianu(s)/ patri piissimo fecerunt h(ic) s(itus) e(st) s(it) t(ibi) t(erra) l(evis).

Mérida, MNAR. Madre de L. Antestius Persicus, IIvir, pontífice perpetuo de la colonia Augusta Emerita.

\section{IULIA QUINTILLA}

a) Cáceres, Norba Caesarina: CIL II 695, 5187; ILER 4869; CPILC 119; CuRChIN 1990, 363; CILC I 145; CuRChIN Supplementum 51 $\mathrm{n}^{\mathrm{o}} 363$.

Q(uinto) Norb(ano) Q(uinti) f(ilio)/Capitoni aed(ili) IIv[iro]/Sulpicia Fausta so[ror]/ et Iulia Quintilla / [u(xor)] /[... ...].

Cáceres. Fachada del palacio del Vizconde de Roda. Esposa de $Q$. Norbanus Capito, IIvir de Norba.

b) Beja, Pax Iulia: CIL II 5187; IRCP 295; CuRCHIN 1990, 383 :

Iulia Q(uinti) f(ilia) Quin/tilla Eborensis/ annorum XXXXII h(ic) s(ita) e(st) s(it) t(ibi) t(erra) l(evis)/Q(uintus) P(etronius?) Mater(nus?) matri.

Beja, Museu Regional. Curchin cree que el dedicante de la inscripción funeraria, Q. P. Mater(nus), puede ser el Q. Petronius Maternus que aparece en dos inscripciones de Pax Iulia (CIL II 47 y $48=$ IRCP 291 y 232), en sendas dedicatorias a Lucio Vero y a Cómodo. A pesar de la homonimia con Iulia Quintilla, esposa de Q. Norbanus Capito, de Norba Caesarina, nos parece poco probable que sea la misma persona, dada la distancia geográfica. La semejanza del nomen es poco significativa, debido a la amplísima distribución y frecuencia del nomen Iulius en Lusitania (AALR, pp. 197-204, s.v.), y tampoco hay medios de establecer o rechazar una proximidad cronológica entre los epígrafes. 


\section{LUCCEIA ALBINA}

Lisboa, Olisipo: CIL II 195; ILER 1660; Gallego Franco 1991, p. 229; RAP 538; De Francisco 1989, p. 130; LefÈvre 2001; DelgaDo 1999 , p. 456, no 17; RodríGUEZ y SaLINAS 2000, p. 252 no 1 ; HEp 14, 2005, 445; $A E$ 2001, 1132; $A E$ 2005, 730; STYLOW y Ventura en Chiron 35, 2005, pp. 36-46; GonZÁLez Herrero 2005; eadem 2006, pp. 55-61, no 9; HEpOl 21284.

Flaminicae/ Provinciae/Lusitaniae/Serviliae L(uci) f(iliae)/Albini d(ecreto) d(ecurionum)// Lucceiae/ Q(uinti) f(iliae) Albinae/ Terentiani/d(ecreto) d(ecurionum).

Pedestal. Perdido actualmente. Es desconocida la relación con la flaminica provincial Servilia L. f., $\left(\mathrm{n}^{\mathrm{o}} 7\right)$ que justificaría la conmemoración conjunta de ambas mujeres. La inscripción de Lucceia estaba grabada en una cara lateral del pedestal, como si se hubiera añadido en un segundo momento.

\section{MANLIA FAUSTINA}

Tavira, Balsa: CIL II 4990, 5162; ILER 5264, IRCP 79; CURCHIN 1990, 319; Gallego Franco 200, 211; RodríGuez y Salinas 2000, 254.

T(ito) Manlio/ T(iti) f(ilio) Quir(ina) Fau/stino Bals(ensis)/ Manlia T(iti) f(ilia)/ Faustina/ soror fra/tri piissimo/IIvir bis/d(ecreto) d(ecurionum)/ epulo dato.

Pedestal. Lisboa, Museu Nacional de Arqueologia. Hermana de $T$. Manlius Faustinus, IIvir bis de Balsa. Finales del s. II.

\section{MARIA PROCULA}

Lisboa, Olisipo: CIL II 193; ILER 5547, CURCHIN 1990, 377; Gallego Franco 211; Rodríguez y Salinas 2000, p. 254; Mantas 2005, 37; Curchin Supplementum 52 no 377.

$D($ is) [M(anibus) s(acrum)]/ L(ucio) Cantio L(uci) f(ilio)/Gal(eria) Marino/ aedili/Vibia Maxima/ avia et/ Maria Procul[a]/ mater honor [e]/ contentae/d(e) s(uo) p(osuerunt).

Madre de L. Cantius Marinus, edil, redime los gastos de los honores que el ordo da a su hijo junto con la abuela, Vibia Severa. Los Cantii parece ser una familia específicamente lusitana, cuyo nomen gentilicium se ha desarrollado sobre una raíz indígena (cf. $A A L R$, p. 132). Aparecen documentados en Idanha-a-Velha (civitas Igaeditanorum) donde un notable local, C. Cantius Modestinus construye un templo a Marte (ManTAS 1993, 233-234) y otro a Venus (MANTAS 1993, 232), además de otro 
en Bobadela al Genius Municipii (CIL II 401) y en Midôes, a la Victoria (CIL II 402). Se documentan también en Mérida (CIL II/ 7, 966; HEp 4, 1994, 156). Cf. ANDREu 2004, 71-77. Vide infra $\mathrm{n}^{\circ} 38$.

\section{PACCIA FLACILLA}

Mérida, Emerita: CIL II 5261; ERAE 31; ILER 179; HEp 2 1990, 36; AE 1987, 484.

[Iovi Aug(usto)/sacrum]/in honorem M(arci) Arriii Reburri/Lanc(iensis) Transc(udani)/ filii optimi/M(arcus) Arrius Laurus et/ Paccia Flaccilla/ posuerunt.

Se trata de un pedestal votivo, reutilizado posteriormente para taller en él un capitel corintio. Solo con dudas incluimos a esta mujer, ya que la reutilización de la pieza impide conocer las circunstancias concretas de la dedicación. La sola muestra de piedad hacia el hijo no basta en nuestra opinión para considerarla una mujer notable.

\section{PROPINIA SEVERA}

S. Salvador de Aramenha, Marvão, Ammaia: CIL II 160; ILER 5518; IRCP 617; RAP 536; RodríGUEZ y SALINAS 2000, 254; $A E$ 2004, 709; HEp 13, 2003-4, 1004.

G(aio) Iul(io) Veget[o]/flamine P[ro]/vinciae L[usita]/niae Propi[nia]/Severa m[ari] to opti[mo].

Placa de mármol. Museu de Ammaia. Esposa de C. Iulius Vegetus, flamen provincial. ILER 5518 lee: Propinia Stafra. Corregimos ahora la lectura que dimos en Rodríguez y SALINAS 2000.

\section{SULPICIA FAUSTA}

Cáceres, Norba Caesarina: CIL II 695, 5187; ILER 4869; CPILC 119; CURCHIN 1990, 363; CILC I 145.

Q(uinto) Norb(ano) Q(uinti) f(ilio)/Capitoni aed(ili) IIv(iro)/Sulpicia Fausta so(ror)/ et Iulia Quintilla/ u(xor).

Cáceres. Fachada del palacio del Vizconde de Roda. Hermana de Q. Norbanus Capito, IIvir en Norba. Cf. comentario al n ${ }^{\circ} 24 a$. La gens Sulpicia parece haber tenido importancia en Lusitania y está bien atestiguada en Conimbriga y en Collippo (AALR 307-308, s.v.).

\section{TOLIA MAXIMA}

Leiria, Collippo: CIL II 349, ILER 4411; CuRChIn 1990, 331; Supplementum $49 \mathrm{n}^{\circ} 331$. 
$D$ (is) M(anibus)/ Toliae/ Maximae/ ann(orum) XXXX/ Claudius/ Tib[e]rianus/ ucsori/ pientissimae.

Tal vez hermana de Tolius Maximus, IIvir en Eburobrittium, según CURCHIN 1990 y Supplementum, aunque no hay pruebas de ello.

\section{TREBIA PROCULA}

Cáparra, Capera: CIL II 814; CPILC 371; RodRÍGuez 2005, 411, no 30; HEpOl 19016; Cerrillo 2006, 20-21; CRC 71; CILC III 1007.

Trebiae/ Proculae/ matri/Cocceia Cel/si filia/Severa/ Norbensis. Pedestal. Actualmente desaparecido. Vide n ${ }^{\circ} 17$.

\section{TREBIA VEGETA}

Cáparra, Capera: CIL II 852; CMPC 279; ILER 4781; CPILC 1; HEpOL 5306; CRC 1; Haba 1986, 24-27 nº 2; Cerrillo 2006, 21-22; CILC III 1006.

Trebiae/Vegetae/ materterae/Cocceia/Severa/ Norbensis.

Pedestal. Vide $\mathrm{n}^{\mathrm{o}} 17$.

\section{TURRANIA CILLEA}

Portalegre, Ammaia: HEp 18, 2009, 583; STYLOW 2009, 35-55; CurChIn, Supplementum 1059.

M(arco) Iunio/ Quir(ina tribu) Gallo / IIvir(o) Turrania / Cilea genero.

Museu de Ammaia. Suegra de M. Iunius Gallus, IIvir de Ammaia. Época Flavia o comienzos del siglo II.

\section{TURRANIA RUFINA}

Conimbriga: AE 1971, 162; EtIenne, Fabre, LévêQue 1976, II, 70; Curchin 1990, 330; Gallego Franco 220; Curchin Supplementum 48,330 .

C(aio) Turranio/ Quir(ina) Rufo/ Turrania Rufina/ soror/ curantib(us)/ M(arco) Val(erio) Pauliano/ cognato et/ L(ucio) Iul(io) Vernacio/socero/ ex testamen(to).

Hermana de C. Turranius Rufus. CuRCHIN 1990 señalaba que los Turranii son una de las familias más prominentes de Conimbriga y que Turranius Rufus podía haber recibido la ciudadanía después de desempeñar una magistratura municipal, pero no hay ninguna prueba de ello. 


\section{VALERIA ALLAGE}

Mérida, Emerita: SAQUETE y Márquez 1993, 63-64, nº 7; AE 1993, 909; HEp 5, 1995, 94; Saquete 1997, 175 n 35; Curchin, Supplementum 1096.

Valeria/ Allage ann(orum) LX h(ic) s(ita) e(st) s(it)/ t(ibi) t(erra) l(evis)/ C(aius) Sulpicius C(aii) f(ilius) Gal(eria tribu) Superstes/ ann(orum) XXXVIII IIvir ter Metellinensim/ huic col(onia) Emeritensis et col(onia) Metelli(nensis)/d(ecreto) d(ecurionum) locum sepulturae et funeris inpen(sam)/decreverunt. $h$ (ic) s(itus) e(st) s(it) t(ibi) t(erra) l(evis).

Lápida. Mérida, MNAR. Esposa de C. Sulpicius Superstes, IIvir ter en Metellinum. Su marido debía ser originario de Metellinum, como indica la adscripción a la tribu Sergia, mientras que la Papiria era la tribu de Mérida. Es probable que Valeria, en cambio, fuera de origen emeritense, lo que explicaría que ambos fueran sepultados en la colonia. Finales del siglo I o siglo II.

\section{VETTILLA PACULI}

Mérida, Emerita: CIL II 468; ILER 237; MÉLIDA 1925, 125 nº 703; ERAE 2; LÉON 1970, 194; ANDREU 2004, 209 nº 17.

Marti sacrum/Vettilla Paculi.

Inscripción monumental sobre la puerta del "Hornito de Santa Eulalia". Cornisa de mármol blanco. Fecha: ca. 184 d.C. LÉON propuso identificarla con la esposa de L. Roscius Paculus, individuo de orden senatorial al que el concilium provinciae dedica una inscripción en Mérida (EE VIII 302; ERAE 97; HEp 15, 2006, 59) por razones desconocidas, que dicha autora suponía que fue el gobierno provincial. Este gobierno ha sido puesto en duda por Caballos 1990, 290 y SAQueTE 1996, 95 y 97-98, quienes plantean un posible origen lusitano del senador para explicar el homenaje.

\section{VIBIA MAXIMA}

Lisboa, Olisipo: CIL II 193; ILER 5547, CURCHIN 1990, 377; Gallego Franco 211, 212.

$D$ (is) [M(anibus) s(acrum)]/L(ucio) Cantio L(uci) f(ilio)/ Gal(eria) Marino/ aedili/ Vibia Maxima/ avia et/ Maria Procul[a]/ mater honor[e]/ contentae/d(e) s(uo) p(osuerunt).

Abuela de L. Cantius Marinus, edil, redime los gastos de los honores dados a él junto con su madre, Maria Procula (cf. n² 27). 
Excluimos de esta lista a Lebisinia Auge, recogida por Álvarez MELERo 2008 79-80. Su suposición de que "nous aurions affaire à un cas d'union entre un haut fonctionnaire et une femme d'extraction locale, au mépris de la loi" nos parece absolutamente conjetural. El hecho de que, como él mismo acepta, el nombre sea un hápax, y de que exista una discordancia entre los nomina del padre y del hijo, es un factor también de duda sobre este epígrafe.

\section{Inscripciones falsae vel suspectae}

\section{A. T[ITA?] AEMILIA MACRINA}

Abrantes, Aritium Vetus?: Beira Alta 12, 1953, 186; CuRCHIN 1990, 316; Rodríguez y Salinas 2000, 254; SiLva 1981, 18-20; CurCHIN Supplementum 47 n 316,109 n $^{\circ}$ 63*.

Inscripción falsa. Cf. HEp 4, 1080.

\section{B. ANÓNIMA}

Beja, Pax Iulia: IRCP p. 300; Del Hoyo 1987, 198-199.

[......]/[a]nn(orum) LV flam[inicae]/ perpetuae civitatis Miri/etanorum pudicissime ac re/[li]giosissimae temporis sui feminael [mat] ri et aviae piissimae fillii?] [e]t nepotes. H(ic) s(ita) e(st) s(it) t(ibi) t(erra) l(evis).

IRCP, p. 300, la rechaza sobre la base de la inexistencia de una desconocida civitas Mirietanorum.

\section{CALCHISIA}

Évora, Ebora: CIL II 122=5189; IRCP p. 443-445 C; ETIENNE 1958, 166, 167; AlmeIDa y Ferreira 1969, 259, fig. 2; AE 1969/70, 214; Del Hoyo 1987, 124-125; RAP 568; Gallego Franco 1991, 229; Delgado 1999, 457, n 18; Rodríguez y Salinas 2000, 252, $\mathrm{n}^{\circ} 2$.

$D$ (is) M(anibus) s(acrum)/memoriae c(larissimae) f(eminae) Calchisiae flam(inicae)/ Prov(inciae) Lusit(aniae) II fil(iae) piisim(ae) et Mar(iae) L(uci) f(iliae)/Sidoniae nept(i) dulc(i)s(simae) et Apon(io) Lu/piano mar(ito) merent(i) fabric(am) qua(m) miser(a) ma/ter Iun(ia) Leonica karis suis et sibi.

Placa de mármol reutilizada en la Edad Media. Montemor-o-Novo, en una pared frontera a la Câmara Municipal. La autenticidad de este epígrafe es muy debatida. IRCP 443-445, notando la rareza de los 
nombres Calchisia, Sidonia y Leonica, y el cultismo fabrica, cree que es una falsificación renacentista. ETIENNE 1958, 221 sin embargo la acepta. Delgado 1999, 458, hace notar que la filiación de los personajes tampoco está exenta de problemas, ya los nombres de las hijas no guardan ninguna relación con los de sus progenitores. A pesar de ello, Delgado cree, con dudas, auténtico el texto.

\section{IUNIA VERECUNDA}

Évora, Ebora: CIL II 115; ILER 5673; IRCP p. 443, B; Del Hoyo 1987, 193-194; Gallego Franco 1991, 227; Rodríguez y Salinas 2000, $252 \mathrm{n}^{\circ} 8$.

C(aio) Antonio C(ai) f(ilio) Fla/vino VIviro iun(iori)/ hasta(to) leg(ionis) II aug(usta) torq(em)/ aur(eum) et an(nonas) dupl(as) ob virt(utem)/donato Iun(ia) Verecun/da flam(inica) perp(etua) mun(icipii) Ebor(ensis)/ mater f(aciendum) c(uravit).

Évora, en la fuente de la plaza. CIL II p. 805 la rechaza, argumentando que Resende habría forjado el texto a partir de CIL V 4365. IRCP p. 443 la rechaza también, aunque observa que, desde el punto de vista paleográfico, es impecable; pero ETIENNE 1958, 239 la admite.

\section{E. LABERIA GALLA}

Évora, Ebora: CIL II 114 (p. XXXVIII, 805); IRCP p. 442 A; DEL Hoyo 1987, 118-120; De Francisco 1989, 131; Gallego Franco 1991, 227; RodrígueZ y Salinas 2000, 252, no 5bis; RAP p. 567; HEp 14, 2005, 441; CANTO, 2004, $281 \mathrm{n}^{\mathrm{o}} 8$ y 332.

Laberiae L(uci) f(iliae)/Gallae fla/minicae munic(ipii)/Eborensis fla/minicae Provin/ ciae Lusitaniae/ L(ucius) Laberius Artemas/ L(ucius) Laberius Callaecus/ L(ucius) Laberius Abascantus/ L(ucius) Laberius Paris/L(ucius) Laberius Lausus/ liberti.

Desaparecida, la división en líneas es decisión de HüBNER, quien la creía falsa, derivada de CIL II 339 (Collippo). IRCP la cree inventada por Resende, como el homenaje a Sertorio por sus libertos (IRCP $\mathrm{n}^{\circ} 30^{*}$ ); pero ETIENNE 1958 (con error en las referencias a $I R C P$ ) p. 223 nota 26, cree insuficientes los argumentos dados por CIL. Del Hoyo, que no distingue entre los dos epígrafes que mencionan al personaje, acepta implícitamente su autenticidad. También CANTO 2004 es partidaria de su autenticidad. 
F. MARTIA C. F.

Cáparra, Capera: CIL II 815; CPILC 184; CRC 65; CuRCHIN 1990, 324; CILC III, 1009.

$D$ (is) M(anibus)/ P(ublio) Aufidio P(ublii) f(ilio) omn(ibus) in rep(ublica)/ hon(oribus) func(to) Martia C(aii) f(ilia) con(iux) b(ene) $m$ (erenti).

Esposa de P. Aufidius, IIvir. CIL la recoge con dudas. Su autenticidad ha sido refutada por GiMENo 1997, 40 y GonZÁLEZ GERMÁn 2012. CILC III, 97, la recoge sin pronunciarse sobre ello.

\section{G. VALERIA TAGANA}

Talavera la Vieja, Augustobriga: CIL II 938, 5343; CPILC 482; Gallego Franco 220; HEp. 10, 2000, 141; HEpOl 6463.

L(ucio) Vibio Quiri(na)/Reburro/Valeria Tagana/Duelonis filia/ testamento poni iussit.

Madrid, Real Academia de la Historia. Inscripción honorífica a $L$. Vibius Reburrus, pontifex, cumpliendo la voluntad ex testamento. De acuerdo con la lectura de Vidal Madruga en HEpOl, no existe la mención de pontifex.

\section{CONCLUSIONES}

Se conocen en la actualidad un total de ocho mujeres que desempeñaron el flaminado del culto imperial. De ellas, dos fueron exclusivamente flaminicae locales (nos. 1: Caelia Vegeta, y 8: Valeria Viniciana); tres fueron flaminicae provinciales (nos. 4: Helvia, 5: Iulia Modesta, y 7: Servilia Albinif.); y tres desempeñaron tanto el flaminado local como el provincial (no 2: Domitia Proculina, 3: Flavia Rufina, y 6: Laberia Galla). Un caso excepcional lo constituye el no 17: Cocceia Severa, si se la identifica con una flaminica provinciae Baeticae et Norbensium mencionada en una inscripción de los Santos de Maimona. En todos los casos anteriores, el flaminado provincial aparece descrito como flaminica provinciae Lusitaniae, de acuerdo con una fórmula estandarizada que se desarrolla a partir de la reestructuración del culto imperial por Vespasiano; por tanto, hay que datar la existencia de estas sacerdotisas a partir del último cuarto del siglo I y a lo largo del siglo II. En el caso de las flaminicae locales que no desempeñaron el sacerdocio provincial (nos. 1 y 8: Caelia Vegeta y Valeria Viniciana), la primera de ellas se 
puede datar con seguridad, por su marido, en época de Adriano. En cuanto a la segunda, la pérdida del monumento impide mayor precisión, pero es probable que se date también en el siglo II. Por supuesto, todas proceden de ciudades que son municipios (nos. 1 y 7: Olisipo; 2: Caesarobriga; 3: Salacia; 5: Bobadela-Conimbriga?; 6: Collippo) o colonias (4 y 8: Emerita), constatándose una mayor presencia en los municipios que en las colonias, como ya observara Étienne (ETIENNE 1990; SALINAS y RoDRíGUEZ 2007).

Estas mujeres ejercieron un auténtico poder social en sus respectivas ciudades que probablemente se extendió, más allá de las mismas, a zonas mayores o menores de la provincia. Iulia Modesta $\left(\mathrm{n}^{\circ} 5\right)$ costeó ex patrimonio suo la construcción de las puertas y el pórtico, probablemente, del foro de su pequeña ciudad, en un alarde de orgullo propio mediante una inversión que debió ser ciertamente costosa. Probablemente antes de ese momento, ya había buscado notoriedad social asociándose a la figura de su marido, Sextus Aponius Scaevus Flaccus, flamen provincial, costeando una estatua a Pietas en honor del mismo, así como de la gens de sus padres, y por tanto suya propia, la gens Iulia. La estatua, probablemente de bronce, debía ser lo suficientemente notable como para no desmerecer la ambición de la dedicatoria. En la medida en que Pietas era la divinización de los deberes para con los dioses y los parentes (RODRÍGuez CoRTÉs 2003), la elección de esta divinidad para una dedicatoria que, en definitiva, conmemoraba el orgullo de su estirpe era algo acertadísimo. Domitia Proculina $\left(\mathrm{n}^{\circ} 2\right)$, en Caesarobri$g a$, estaba probablemente emparentada con Domitia Attia, esposa de $L$. Annius Placidus que fue tres veces duovir de la ciudad, en la cual debía haber una gens Domitia acomodada. Flavia Rufina $\left(\mathrm{n}^{\mathrm{o}} 3\right)$ fue flaminica en Salacia, de donde era natural, pero también en Mérida, además de desempeñar el flaminado provincial.

El evergetismo público constituyó un medio eficaz para estas mujeres de obtener notoriedad a la vez que de expresar su influencia. Hemos visto a Iulia Modesta $\left(\mathrm{n}^{\circ} 5\right)$ costeando las obras públicas de su ciudad. Otras mujeres ornan con sus estatuas los foros locales ex decreto decurionum (nos. 3 y 7) o reciben un monumento póstumo de la misma manera $\left(\mathrm{n}^{\mathrm{o}} 6\right)$. Este comportamiento se observa también en otras mujeres que, aunque no consta que desempeñaran el flaminado, sin duda tenían un nivel de influencia social dado que sus maridos eran magistrados de sus ciudades respectivas. Es el caso de Iulia Luperca $\left(\mathrm{n}^{\mathrm{o}} 21\right)$, esposa de M. Fidius Macer. Este individuo debía ser uno de los sujetos 
más importantes de Capera, a juzgar por el hecho de que desempeñó tres veces la magistratura local antes de la conversión municipal de la ciudad y, posteriormente, fue dos veces duovir de la misma. La potencia política y económica de los Fidii caparenses quedó explicitada mediante la construcción del tetrapilo que daba acceso al foro, adornado con los retratos ecuestres de Fidius Macer y sus antepasados. Pero en otro de los paramentos el magistrado hizo representar también a su esposa con la correspondiente dedicatoria.

Un caso notable, en este sentido, es el del conjunto de dedicatorias con las que Cocceia Severa, natural de Norba Caesarina pero afincada en Capera, conmemoró a su abuela Avita, a su madre Trebia Procula y a su tía materna Trebia Vegeta (nos. 12, 32 y 33). Dichas dedicatorias se conservan en pedestales de mármol sobre los cuales iban las estatuas de las aludidas que ornaban el pórtico del foro de la ciudad. Es notable que en ninguna de las inscripciones se aluda a los varones de la familia, salvo por la preceptiva mención de la filiación, y no sabemos si este rasgo se debe relacionar o no con relaciones familiares de tipo indígena. El hecho de que la abuela, Avita, sólo mencione el cognomen hace pensar que era inicialmente de estatuto peregrino y que obtuvo retroactivamente la ciudadanía. Las relaciones sociales y económicas de Cocceia Severa con su ciudad de origen, Norba, se conservaron sin embargo, ya que se documenta la presencia de un esclavo y de un liberto que son verosímilmente suyos en Malpartida de Cáceres, en el territorium de la colonia. La identificación, anteriormente mencionada, con una flaminicae provinciae Baeticae et Norbensium mostraría que llegó a desempeñar el flaminado de su ciudad de origen.

En los casos de mujeres que no han desempeñado el flaminado pero que se asocian a las figuras de parientes para alcanzar visibilidad social observamos que la relación uxor/maritus es la más frecuente (11 veces), junto con la relación mater/filius, $-a$ (10 veces). Otras relaciones como las de soror/frater (3 veces) pater/filia (2 veces) avia/neptis (2 veces), etc., son mucho menos frecuentes. A veces, estas mujeres hacen constar que erigen la inscripción de suo (nos. 15, 38), o que añaden una dádiva, por ejemplo: epulo dato $\left(\mathrm{n}^{\mathrm{o}} 26\right)$.

Dada la parquedad de datos con que contamos, es prácticamente imposible establecer una evolución. No obstante, y a riesgo de equivocarnos en nuestras conclusiones, si tenemos en cuenta que alguna de ellas dice ser flaminica prima et perpetua $\left(\mathrm{n}^{\circ}\right.$ 2: Caesarobriga) o flaminica perpetua (nos. 3 y 8: Salacia y Emerita), estas expresiones dan a 
entender que el elenco de flaminicae fue restringido, ya que el cargo no se renovaba anualmente, sino que en ocasiones era necesario esperar al fallecimiento de una para proceder a la elección de otra nueva sacerdotisa. Si tenemos en cuenta que no podemos datar con seguridad en el siglo III ninguna de las inscripciones que aluden a ellas, alcanzamos la sensación de que el flaminado femenino, local y provincial, se desarrolló a partir de la reforma del culto realizada por Vespasiano, incentivado seguramente por la conversión de ciudades peregrinas en municipios Flavios y el deseo de las élites locales de mostrar su adhesión al poder imperial y ostentar un modo de vida romano. Pero pasadas tres o cuatro generaciones, hacia finales del siglo II o comienzos del siglo III, parece que este fervor decayó, debido en gran medida también a las dificultades económicas que comenzaron a afectar a los municipios.

Corrigenda: en una visita reciente al Museo del Teatro Romano de Lisboa hemos podido comprobar, gracias a la amabilidad de su directora, la Dr. ${ }^{a}$ Lídia Fernandes, que la inscripción referente al $\mathrm{n}^{\circ} 19$, Heia, en realidad no menciona a la supuesta esposa de C. Heius Primus, como la Bibliografía ha ido repitiendo, sino que tras el nombre de éste debe suplirse [dedit]. Heia, por tanto, debe eliminarse del catálogo.

\section{ABREVIATURAS}

$A A L R=$ Atlas antroponímico de Lusitania romana Grupo Mérida (Navarro Caballero,

Milagros y Ramírez Sádaba José Luís, coords.) (2003) Mérida-Burdeos.

$\mathrm{AE}=L^{\prime}$ Année Epigraphique

$B R A H=$ Boletín de la Real Academia de la Historia

CIL II = HÜBNER, Emil Corpus Inscriptionum Latinarum II: Inscriptiones Hispaniae latinae Berlin 1869; supplementum Berlin 1892.

$C I L C=$ EsteBAN OrTEgA, Julio (2007-2013) Corpus de inscripciones latinas de Cáceres vols. I-III Cáceres.

$C M P C=$ MÉLIDA, José Ramón (1924) Catálogo monumental de España. Provincia de Cáceres Madrid.

CPILC = HuRTADO DE SAN ANTONIO, Ricardo (1977) Corpus provincial de inscripciones latinas de Cáceres Cáceres.

$C R C=$ Río-Miranda, Jaime, (2010) La ciudad romana de Cáparra. Municipium Flavium Caparensis Plasencia.

EJER = D'ors, Álvaro (1953) Epigrafía jurídica de la España Romana Madrid.

$E E=$ Ephemeris Epigraphica Berlin.

ERAE = GARCÍA IGLESIAS, Luís (1973) Epigrafia romana de Augusta Emerita tesis doctoral inédita Madrid.

HAEp = Hispania Antiqua Epigraphica .

Conimbriga, 55 (2016) 221-250 
HEp = Hispania Epigraphica

HEpOl = Hispania Epigraphica on line

ILER = VIVES, Jaime (1971-1972) Inscripciones latinas de la España romana Barcelona.

ILS = DeSSAU, H. Inscriptiones latinae selectae Berlin $1892-1916$.

$I M B A=$ Salas, José, Esteban, Julio y Redondo, José Antonio (1997) Inscripciones romanas y cristianas del museo arqueológico provincial de Badajoz Badajoz.

IRCP = ENCARNAÇÃo, José d', (1984) Inscriçôes romanas do conventus Pacensis Coimbra.

MMAP = Memorias de los Museos Arqueológicos provinciales

RAP = Garcia, José Manuel (1991) Religiôes antigas de Portugal. Fontes epigrâficas Lisboa.

\section{BIBLIOGRAFÍA}

Abascal Palazón, Juan Manuel (1994a) Los nombres personales en las inscripciones latinas de Hispania Murcia.

Abascal Palazón, Juan Manuel (1994b) "Inscripciones romanas y celtibéricas en los manuscritos de Fidel Fita en la Real Academia de la Historia" Archivo de Prehistoria Levantina 21 367-390.

Abascal Palazón, Juan Manuel y Alföldy, Géza (2015) Inscripciones romanas de la provincia de Toledo (siglos I-III) Madrid.

AlFöldy, Géza (1969) Fasti Hispanienses Wiesbaden.

AlFöLDY, Géza (1987) Römisches Städtewesen auf der neukastilichen Hochebene Heidelberg,.

Almeida, Justino Mendes de y Ferreira, Francisco Bandeira (1969) "Varia Epigraphica" Rev. de Guimarães 79, 257-262.

Álvarez Melero, A. (2009) "Matronae equestres ex provincia Lusitania ortae” RBPh 86 69-95.

Álvarez Saenz de Buruaga, José (1943) "Museo Arqueológico de Mérida (Badajoz)', MMAP 4 44-52.

ANDREu Pintado, Javier (2004) Munificencia pública en la provincia Lusitania (siglos $I-I V$ d.C.) Zaragoza.

BlázQuez MarTínez, José María (1965) Cáparra I Madrid.

Brandẽo, Domingos de Pinho (1972) "Epigrafia romana coliponense" Conimbriga 11 41-192.

Caballos Rufino, Antonio (1990) Los senadores hispanorromanos y la romanización de Hispania (s. I-III) I: Prosopografía Écija.

IDEM (1998) "Los equites y la dinámica municipal de la Lusitania. I.: catálogo prosopográfico", en L. Hernández Guerra y L. Sagredo San Eustaquio (eds.), El proceso de municipalización en la Hispania romana. Contribuciones para su estudio Valladolid 205-233.

Conimbriga, 55 (2016) 221-250 
CAnto, Alicia Ma . (2004) "Los viajes del caballero inglés John Breval a España y Portugal: Novedades arqueológicas y epigráficas de 1726.” Revista Portuguesa de Arqueologia 7/2 265-364.

Cerrillo, Enrique (2006) "La monumentalización del foro de Cáparra a través de la epigrafía”, en D. VAquerizo y F. J. Murillo (eds.), El concepto de lo provincial en el mundo antiguo. Homenaje a la profesora Pilar León Alonso Córdoba 13-30.

CurChin, Leonard (1990) The local magistrales of Roman Spain Toronto.

CurChIn, Leonard (2015) A supplement to the local magistrates of Roman Spain libro digital Waterloo.

De Francisco Martín, Julián (1989) Conquista y romanización de Lusitania Salamanca.

Delgado Delgado, José A. (1999) “Flamines provinciae Lusitaniae" Gerión 17433 461.

Delgado Delgado, José A. (2000) "Los sacerdotes de rango local de la provincia romana de Lusitania" Conimbriga 39 107-15.

Del Hoyo Calleja, Javier (1987) La importancia de la mujer hispanorromana en la Tarraconense y Lusitania a la luz de los documentos epigráficos. Aspectos religiosos y socioeconómicos Tesis doctoral Madrid.

D'EncarnaÇão, J. (2014) "A inscriçâo e o seu duplo: o caso da flaminica Laberia Galla”, en A. Donati (ed.) L'iscrizione e il suo doppio. Atti del Convegno Borghesi 2013 Faenza 411-428.

DíAz DE Cerio, M (2012) "Los senadores originarios de Lusitania (1982-2012) / The Lusitanian senators (1982-2012)", Espacio, Tiempo y Forma, Serie II: Historia Antigua, 25 327-354.

Edmondson, Johnatan, Nogales Trinidad y Trillmich, Walter, (2001) Imagen y Memoria. Monumentos funerarios con retratos en la Colonia Augusta Emerita Madrid.

ETIEnNe, Robert (1958) Le culte imperial dans la Péninsule Ibérique Paris.

ETIENNE, Robert (1990) "Le culte imperial, vecteur de la hiérarchisation urbaine" Les villes de Lusitanie romaine Paris 215-231.

Etienne, R., Fabre, G., LÉVÊQue, M., LÉVÊQue, P. (1976) Fouilles de Conimbriga, II: épigraphie et sculpture Paris.

FernANDes, Luís da Silva (2003) "Inscrições romanas do termo de Loures" Máthesis 12 28-33 n 1 fotos $1-2$.

Fita Colomé, Fidel (1882) "Inscripciones romanas de la ciudad y partido de Talavera (Provincia de Toledo)", BRAH 2 259-260.

Fuidio RodríGuez, Fidel (1934) Carpetania romana Madrid.

Gallego Franco, Henar (1991) Femina dignísima. Mujer y sociedad en Hispania antigua Valladolid.

GAMER, Gustav (1989) Formen römischer Altäre auf der Hispanischen Halbinsel, Madrider Beiträge 12 Mainz.

Gimeno, Helena (1997) Historia de la investigación epigráfica en España en los ss. XVI y XVII, a la luz del recuperado manuscrito de Guimerá Zaragoza.

Conimbriga, 55 (2016) 221-250 
Gómez-Pantoja, J. y Madruga, J.-V. (2014) "Flaminica provinciae Baeticae et Norbensium", en A. Caballos Rufino y E. Melchor Gil De Roma a las provincias: las elites como elemento de proyección de Roma Córdoba-Sevilla 247-272.

González Conde, María Pilar (2000) “Cocceia Severa y los Cocceii hispanos” HA 24 165-173.

GonZÁLEZ Germán, Julián (2012) “Una inscripción (falsa) más de Cáparra” ZPE 183 297-305.

GonzÁLez Herrero, Marta (2002) “M. Fidius Fidi f. Quir(ina) Macer, benefactor en Capera" Gerión 20 417-433.

GonzÁlez Herrero, Marta (2005) "El abogado olisiponense Lucceius Albinus y familia." Revista Portuguesa de Arqueología 8/1 243-55.

GonzÁlez Herrero, Marta (2006) Los caballeros procedentes de la Lusitania romana Madrid.

Haba Quirós, S. (1986) Catálogo epigráfico del partido judicial de Plasencia memoria de Licenciatura inédita Cáceres.

Immongault Nomewa, Roselyne (2006) La femme romaine dans l'épigraphie latine de la période augustéenne au deuxième siècle après Jésus-Christ: une approche régionale (Rome et l'Italie) Paris.

LAMBrino, Scarlat (1951) "Inscriptions latines du Musée Leite de Vasconcelos" O Archeologo Portugues (n.s.) 1 37-61.

Lefèbvre, Sabine (2001) “ ¿Q. (Lucceius Albinus), Flamen Provinciae Lusitaniae? L'origine sociale des flamines provinciaux de Lusitanie." Élites Hispaniques M. Navarro y S. Demougin (eds.) Burdeos 217-39.

León Alonso, Pilar (1970) "Los relieves del templo de Marte en Mérida" Habis 1 181-197.

Mantas, Vasco Gil (1993) "Evergetismo e culto oficial: o constructor de templos C. Cantius Modestinus" Religio deorum (M. Mayer ed.) Sabadell 227-250.

Mantas, Vasco Gil (2005) "Os magistrados olisiponenses do periodo romano" Turres Veteras 7 23-56.

Melchor Gil, E. (2009) "Mujeres y evergetismo en la Hispania romana", en J. F. Rodríguez NeIla (ed.), Hispania y la epigrafia romana. Cuatro perspectivas, Faenza 133-178.

Mirón PÉREZ, Dolores (1996) Mujeres, religión y poder: el culto imperial en el occidente mediterráneo Granada.

NAVARro CABAllero, M. (2001) "Les femmes de l'élite hispano-romaine, entre la famille et la vie publique", en M. Navarro Caballero y S. Demougin (eds.) con la colaboración de F. des Boscs-Plateaux, Elites hispaniques, Burdeos 191-201.

IDEM (2003) "Mujer de notable: representación y poder en las ciudades de la Hispania imperial", en S. Armani, B. Hurlet-Martineau y A. U. Stylow (eds.), Epigrafia y sociedad en Hispania durante el Alto Imperio: estructuras y relaciones sociales. Actas de la Mesa Redonda organizada por la Casa de Velázquez, el 
Centro CIL II de la Universidad de Alcalá y L'Année Épigraphique, Madrid-Alcalá de Henares, 10-11 de Abril de 2000 Madrid-Alcalá de Henares 119-127.

Nogales Basarrate, Trinidad (1997) El retrato privado en Augusta Emerita, vols. I-II Badajoz.

Nogales Basarrate, Trinidad (1998) "Catálogo de piezas. 273. Estela funeraria de L. Antestius Persicus” Hispania. El legado de Roma. En el año de Trajano (La Lonja - Zaragoza. Septiembre - noviembre de 1998) Zaragoza - Madrid.

Raepsaet-Charlier, M.-Th. (1987) Prosopographie des femmes de l'ordre sénatorial (I ${ }^{e r}$-II ${ }^{e}$ siècle) Lovaina.

Rodríguez Plaza, Miguel Ángel (2005) "Epigrafía latina de Oliva de Plasencia” REE $61 \mathrm{n}^{\circ} 2385-422$

RodríGuez Cortés, Juana (2003) "Pietas erga deos. La piedad hacia los dioses en la Bética romana" Actas del III Congreso de Historia de Andalucía Córdoba 431-442.

Rodríguez Cortés, Juana y SALinAS DE FríAs, Manuel (2000) “Las élites femeninas en la provincia romana de Lusitania" SHHA 18 243-255.

SALINAS de Frías, Manuel y RodríGuez CortÉs, Juana (2007) "El culto imperial en el contexto político y religioso del conventus Emeritensis" Culto imperial: política $y$ poder Roma 159-178.

Saquete Chamizo, José Carlos (1996) Las élites sociales de Augusta Emerita Mérida.

Saquete Chamizo, José Carlos y Márquez Pérez, Joaquín. (1993) "Nuevas inscripciones romanas de Augusta Emerita: la necrópolis del Disco" Anas 6 51-74.

Silva, Joaquim Canderas da (1981) "Epigrafia romana de Abrantes: quatro textos em questâo" Trebaruna 19-24.

STYLOW, Armin U. (1993) "Decemviri. Ein Beitrag zur Verwaltung peregriner Gemeinden in der Hispania Ulterior" Ciudad y comunidad cívica en Hispania (siglos II y III d. C.) Madrid 37-46.

IDEm (2009) "O estatuto jurídico de Ammaia, a propósito de uma inscrição copiada em 1810" Ibn Maruán 16 no. Marvão e Ammaia ao tempo das guerras peninsulares $35-55$.

Stylow, Armin U., y Ventura, A. (2005) "Doppelstatuenpostamte und virtuelle Statuen. Neues zu Lukans vorfahren Mütterlicherseits und zu CIL II 195 aus Olisipo." Chiron 35 36-46.

Trillmich, Walter; Hauschild, Theodor; Blech, Michael; Niemeyer, Hans G.; NúNNerich-Asmus, Annette (1993) Hispania Antiqua. Dekmäler der Römerzeit Mainz del Rin.

VASCONCelos, José Leite de (1913) Religiões da Lusitânia vol. III Lisboa.

VAsConcelos, José Leite de (1927-29) "Epigrafia do Museo Etnologico (Belem). Inscrições romanas" O Archeologo Português 28 209-227.

VelázQuez JimÉnez, Agustin (1988) "Una Helvia, flaminica en Augusta Emerita" Anas 1 125-132.

WIEGELS = Wiegels, Rainer (1985) Die Tribusinschriften des römischen Hispanien. Ein Katalog Berlín.

Conimbriga, 55 (2016) 221-250 